\title{
Comunicación
}

\section{CARCINOMA DE CÉLULAS TRANSICIONALES EN PERROS: UN INFORME DE DOS CASOS, MADRE E HIJA}

\author{
Transitional Cell Carcinoma in Dogs: a Report of two cases, mother and \\ DAUGHTER
}
Leonardo Martins Leal ${ }^{1,4}$, Márcia Rita Fernandes Machadoํㅜ, Fernanda Bignotto Ferreira $^{2}$, Eliangela Margarete Didonée ${ }^{2}$ Isabela Bruno de Souza ${ }^{3}$

\section{Resumen}

El carcinoma de células transicionales que comúnmente se encuentra en la región del trígono de la vejiga se presenta con signos inespecíficos de las vías urinarias inferiores, tales como hematuria, estranguria, poliaquiuria e incontinencia urinaria. Las obstrucciones uretrales y ureterales ocurren en algunos casos. Factores etiológicos, endógenos e iatrogénicos han sido catalogados como la causa de la enfermedad. El presente reporte tiene como objetivo hacer la descripción y tratamiento de dos casos de carcinoma de células transicionales presentado en forma simultánea en dos perras. Se presenta el caso de madre e hija con hematuria y azotemia post-renal, y las dos con tumor en el trígono de la vejiga. Después de la cistectomía parcial con ureteroneocistostomía, el diagnóstico de carcinoma de células transicionales fue confirmado por análisis histopatológico del tejido seccionado de la vejiga. Las pacientes recibieron firocoxib como adyuvante a la cirugía. Se concluye que el procedimiento quirúrgico asociado con el uso de antiinflamatorios COX-2 específicos proporcionó una mejor calidad de vida de los pacientes.

Palabras clave: carcinoma, hematuria, vejiga, perro

\section{Abstract}

The transitional cell carcinoma is usually located in the trigone region of the bladder, and shows nonspecific clinical signs of the lower urinary tract such as hematuria, strangury, pollakiuria and urinary incontinence. The urethral and ureteral obstructions occur in some cases. Etiological factors such as endogenous and iatrogenic have been listed as the cause of disease. The objective of this report is to describe the process and treatment of two cases of transitional cell carcinoma presented simultaneously in two

1 Departamento de Morfología y Fisiología Animal, Laboratorio de Anatomía, Facultad de Ciencias Agrarias y Veterinarias, UNESP, Jaboticabal-SP, Brasil

2 Clinicão Didoné, Santa Barbara D’Oeste-SP, Brasil

3 Universidad de Morón, Provincia de Morón, Buenos Aires, Argentina

4 E-mail: leonardo.vet@hotmail.com 


\begin{abstract}
dogs, mother and daughter, that showed hematuria and post-renal azotemia, both with tumor in the trigone of bladder. After partial cystectomy ureteroneocistostomia, the diagnosis of transitional cell carcinoma was confirmed by histopathological analysis of bladder tissue. Patients received firocoxib as adjuvant to surgery. It is concluded that the surgical procedure associated with the use of specific anti-inflammatory COX-2 provided a better quality of life in both patients.
\end{abstract}

Key words: carcinoma, hematuria, bladder, dog

\section{INTRODUCCIÓN}

El carcinoma de células transicionales, también llamado carcinoma urotelial invasivo de vejiga, es el tumor vesical más común en los perros, afectando principalmente a hembras entre 9 y 10 años. La etiología del cáncer de vejiga es generalmente multifactorial. Dentro de estos, se puede mencionar a factores iatrogénicos en pacientes tratados con ciclofosfamida y a exposiciones repetidas a insecticidas, especialmente los utilizados en los baños anti-pulgas, así como factores endógenos e intrínsecos, tales como productos derivados de la acción de los metabolitos de triptofano y la obesidad, una vez que la grasa almacena agentes cancerígenos, especialmente los compuestos hidrofóbicos (Knapp, 2007; Carvalho y De Brum, 2009).

Los tumores pueden ocasionar obstrucción parcial o completa de los uréteres y la uretra; además, ocasionan metástasis en el $50 \%$ de los casos, los cuales comúnmente involucran pulmones, ganglios linfáticos, riñones, hígado y próstata. También se reportan metástasis en huesos largos, cráneo y ojos (Carvalho y De Brum, 2009; Rossetto et al., 2009).

Hematuria, poliaquiuria, estranguria o incontinencia urinaria son los signos clínicos más comunes y se parecen a otros trastornos del tracto urinario inferior. En los casos de obstrucción, la azotemia post-renal está presente y el paciente puede presentar anorexia, malestar general y vómitos (Valsecchi et al., 2005; Carvalho y De Brum, 2009).
El diagnóstico de tumor vesical se realiza mediante imágenes de doble contraste radiográfico, ecografía, cistoscopía, tomografía y resonancia magnética. Sin embargo, para identificar el origen del tumor, es necesario el análisis histopatológico (Ware, 2006).

El tratamiento de elección es quirúrgico en los casos en que la región del trígono no se encuentre afectada. El uso de antiinflamatorios no esteroideos (AINE) ayuda a controlar el desarrollo del tumor (Fossum, 2008). El pronóstico es malo, y el paciente puede sobrevivir sin tratamiento de cuatro a seis meses, y con la cirugía puede extender su periodo de vida entre seis meses a un año (Chun, 2008).

El presente estudio tuvo como objetivo describir dos casos de carcinoma de células transicionales presentados en dos perras, madre e hija.

\section{Reporte de un Caso}

Se trabajó con dos pacientes de especie canina, mestizos, madre e hija, de 14 y 13 años y 8.5 y $10 \mathrm{~kg}$ de peso, respectivamente, en una clínica veterinaria en Santa Bárbara D’Oeste, Brasil. Los canes habrían presentado hematuria por 15 días.

Se realizó la anamnesis, el examen físico general y las pruebas de laboratorio. La madre presentaba azotemia post-renal, pero la hija no. Los resultados de los hemogramas 


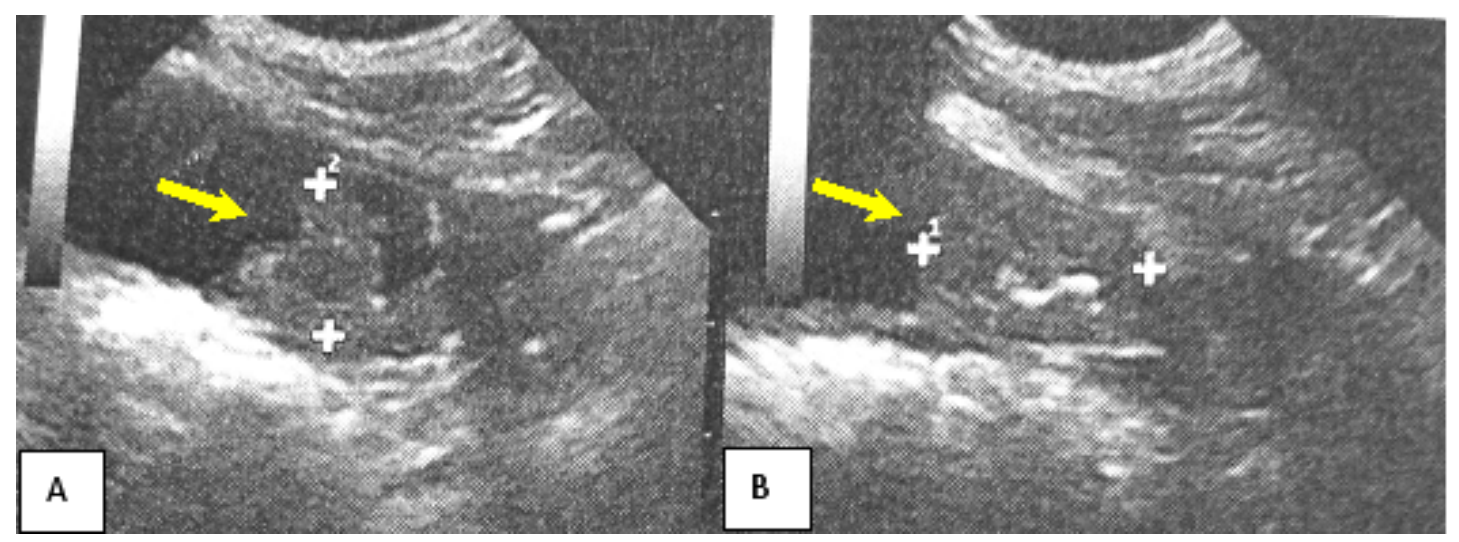

Figura 1. Imagen de ecografía de vejiga en una perra mestiza de 14 años con cáncer de vejiga. Se nota neoformación intraluminal de $1.5 \mathrm{~cm}$ de diámetro (flecha). A: posición longitudinal. B: posición transversal

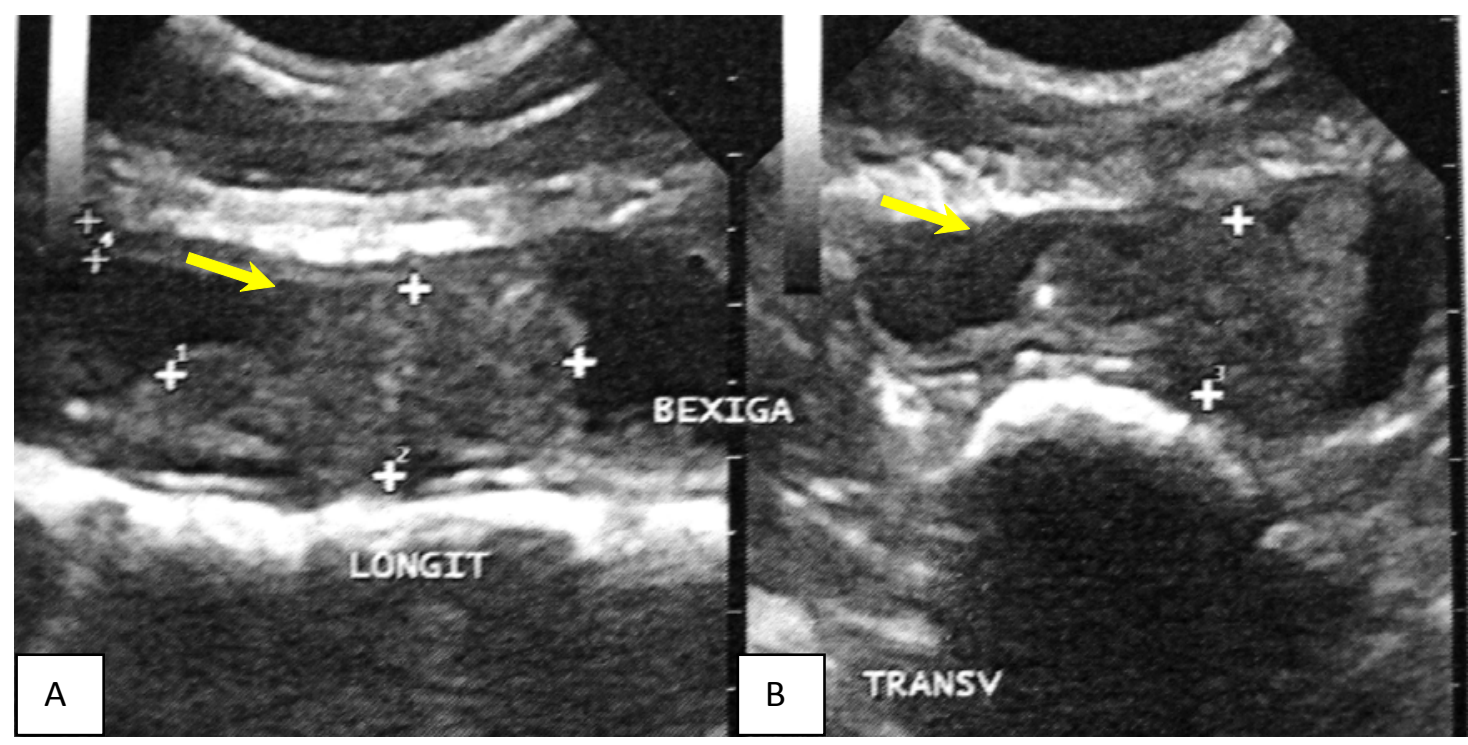

Figura 2. Imagen de ecografía de vejiga en una perra mestiza de 13 años con cáncer de vejiga. Se nota neoformación intraluminal de $2.5 \mathrm{~cm}$ de diámetro (flecha). A: posición longitudinal. B: posición transversal

de la madre y de la hija estaban normales. En el examen ecográfico, se detectó una masa en el trígono de la vejiga en las dos perras. En la madre, se visualizó dilatación de las pelvis renales, hidrouréter bilateral y la masa de $1.5 \mathrm{~cm}$ de diámetro estaba obstruyendo la llegada ureteral. En la hija, el tumor era más grande, de unos $2.5 \mathrm{~cm}$, pero sin obstrucción de los uréteres (Figs. 1 y 2). Se practicó citología de aspiración con aguja fina (CAAF) guiada por ecografía en ambos casos.

Dada la sospecha de carcinoma, las pacientes se sometieron a laparotomía exploratoria y posterior cistectomía parcial (Fig. 3). Los uréteres se colocaron en un área de la vejiga macroscópicamente sana y se procedió a seccionar cerca del $50 \%$ de la vejiga. 


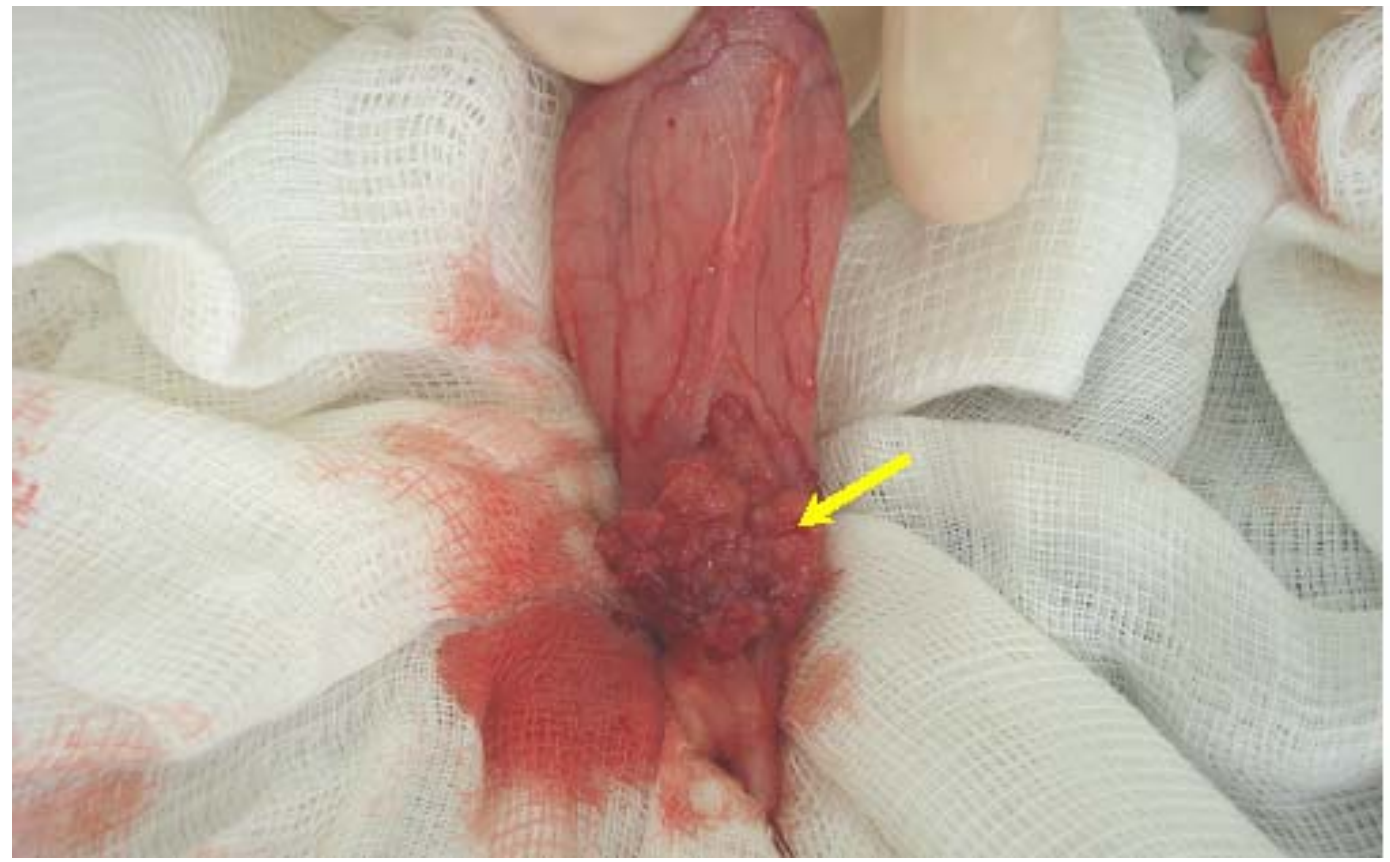

Figura 3. Imagen fotográfica intraoperatoria de vejiga de una perra mestiza de 13 años con cáncer de vejiga. Después de la cistostomía ventral cerca de la uretral, se nota neoformación intraluminal no capsulada en la región del trígono (flecha)

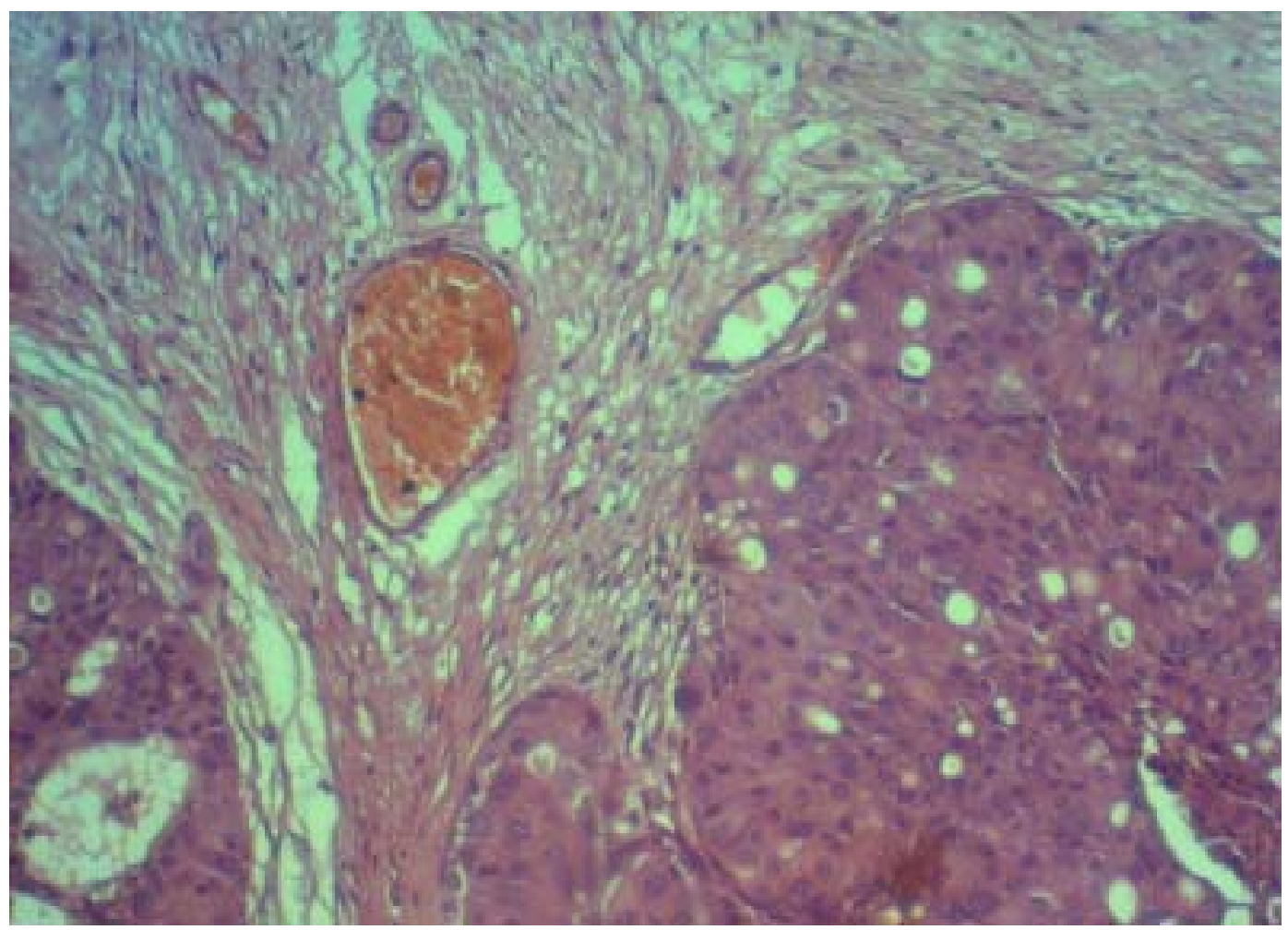

Figura 4. Tumor intravesical en una perra mestiza de 14 años. Se visualiza células epiteliales con alto pleomorfismo nuclear, núcleo grande, nucléolos múltiples, numerosas figuras de mitosis y citoplasma eosinofílico voluminoso con presencia de invasión linfática. HE, 400x 


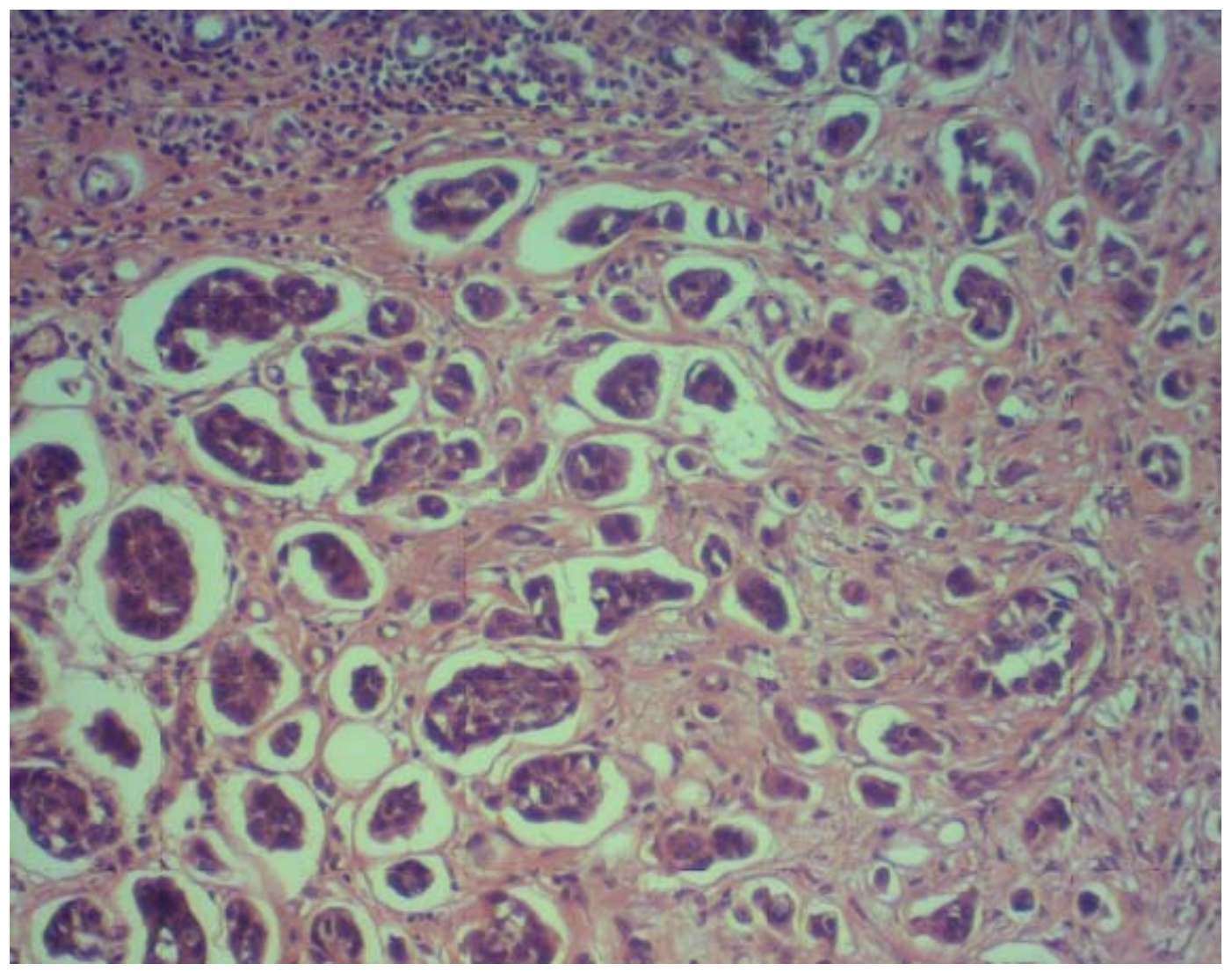

Figura 5. Tumor intravesical en una perra mestiza de 13 años. Se visualiza células epiteliales con alto pleomorfismo nuclear, núcleo grande, nucléolos múltiples, numerosas figuras de mitosis y citoplasma eosinofílico voluminoso con presencia de invasión linfática. HE, 400x

La histopatología del tejido seccionado de la vejiga en las dos hembras confirmó la sospecha de carcinoma de células transicionales. Se visualizó en ambos casos, neoplasia maligna invadiendo el corion de la vejiga, caracterizado por células epiteliales con alto polimorfismo nuclear, núcleos grandes, nucléolos múltiples, numerosas figuras de mitosis y citoplasma eosinofílico voluminoso, con presencia de invasión linfática, y de conformidad con carcinoma de células transicionales (Figs. 4 y 5).

Se prescribió ranitidina $(2.2 \mathrm{mg} / \mathrm{kg}$ cada 12 horas, 10 días), enrofloxacina (5 mg/kg cada 12 horas, 10 días), clorhidrato de tramadol ( $2 \mathrm{mg} / \mathrm{kg}$ cada 8 horas, 5 días) y firocoxib (5 mg/kg cada 24 horas, 30 días).
Después de cinco días de la cirugía, las pacientes no presentaban hematuria y la madre estaba con incontinencia urinaria nocturna leve.

\section{Discusión}

La madre, después de 30 días de la cirugía, estaba con los valores séricos de creatinina y urea dentro de los límites normales; sin embargo, a los 90 días de la operación, la paciente volvió a presentar cuadros de hematuria y la ecografía visibilizó de nuevo una masa en la región trigonal; se prescribió nuevamente firocoxib pero el cuadro clínico evolucionó en vómitos intensos, malestar y anorexia, de modo que se procedió con 
la eutanasia del animal a los 120 días de la cirugía.

En la hija, después de 6 meses de la operación, aunque sin alteraciones clínicas, se realizó una ecografía para comprobar si había recurrencias. La imagen ecográfica identificó hidronefrosis leve en el riñón derecho y dos masas en la región de trígono con 1.78 x $0.90 \mathrm{~cm}$ y 1.16 x $0.31 \mathrm{~cm}$. Se prescribió una vez más firocoxib (5 mg/kg cada 48 horas) por un periodo indefinido. En la actualidad, a los 11 meses de la cirugía, el paciente continúa recibiendo firocoxib cada 48 horas, y a pesar del diagnóstico por ecografia, no hay signos clínicos compatibles con cáncer de vejiga.

La etiología del cáncer es aún incierta, donde diversos factores iatrogénicos y endógenos se mencionan como posibles causas (Knapp, 2007; Carvalho y De Brum, 2009). Asimismo, factores génicos se han descrito en la raza Scotch Terrier (Knapp, 2007). En el presente reporte, a pesar de no haber hecho ningún estudio genético, se puede pensar en una posible relación hereditaria ya que la madre y la hija presentaron la misma neoformación, sin que hayan sido expuestas a potenciales agentes carcinógenos.

La literatura científica describe a la cistografía de doble contraste como el método más adecuado para identificar un proceso de tumor intravesical (Ware, 2006); sin embargo, la ecografía practicada en los pacientes mostró una imagen clara de neoformación intraluminal, la cual permitió, además, proceder a realizar un procedimiento de CAAF.

La cirugía en tumores localizados en el trígono vesical no está indicada debido a que el fuerte carácter invasivo del carcinoma compromete la margen quirúrgica en la mayoría de los casos, como se observó en el trabajo de Knapp (2007) con 67 perros con carcinoma de células transicionales de la región del triángulo y que fueron sometidos a cistectomía parcial. Sin embargo, las pacientes en cuestión fueron sometidas a la cistectomía parcial con ureteroneocistostomía, especialmente debido a la obstrucción ureteral presente en una de las hembras y a la hematuria que estaba presente en ambos canes, lo cual proporcionaba un medio adecuado para la proliferación de bacterias en la vejiga.

Los AINEs son indicados como medicamentos contra el cáncer. Piroxicam es el medicamento más comúnmente utilizado. Knapp (2007) informó la remisión total del tumor en dos pacientes con la sola utilización de este fármaco. Sin embargo, se presentan efectos adversos como vómitos y úlcera gástrica (Fossum, 2008).

Khan et al. (2000), para evaluar la expresión de COX-1 y COX-2 mediante métodos inmunohistoquímicos en perros sanos y aquellos con carcinoma de células transicionales, determinaron que los pacientes con cáncer sólo expresan la COX-2 en el epitelio de los tumores primarios y en las lesiones metastásicas. Por lo tanto, en el presente caso, se optó por utilizar firocoxib, AINE COX-2 específicos, que tiene menos efectos secundarios que el piroxicam, sobre todo, por la necesidad de un uso prolongado.

Rossetto et al (2009) reportó un periodo de supervivencia de dos años en un perro con carcinoma de células transicionales tratados sólo quirúrgicamente, indicando además, que el diagnóstico y el tratamiento precoz aumenta la supervivencia del paciente. En el presente estudio, el proceso tumoral en la progenitora se encontraba en un estadio más avanzado y con obstrucción uretral, teniendo una supervivencia más corta que la hija, la cual no presentaba obstrucción ureteral en el momento del diagnóstico.

ConCLusión

El procedimiento quirúrgico asociado con el uso de AINES COX-2 específicos ofreció una mejor calidad de vida a los pacientes. 


\section{Literatura CitAdA}

1. Carvalho MB, De Brum AM. 2009. Neoplasias do sistema urinário. En: Daleck CR, De Nardi AB, Rodaski S (eds). Oncologia em cães e gatos. São Paulo: Roca. p 392-396.

2. Chun R. 2008. Carcinoma das células transicionais renais, vesicais e uretrais. En: Tilley LP, Smith Jr FWK (eds). Consulta veterinária em 5 minutos. Espécies canina e felina. $3^{\mathrm{a}}$ ed. Barueri, Brazil: Manole. 272 p.

3. Fossum TW. 2008. Cirurgia do rim e ureter. En: Cirurgia de pequenos animais. $3^{\mathrm{a}}$ ed. São Paulo: Elsevier. p 658-660.

4. Khan KN, Knapp DW, Denicola DB, Harris RK. 2000. Expression of cyclooxygenase- 2 in transitional cell carcinoma of the urinary bladder in dogs. Am J Vet Res 61: 478-481.
5. Knapp DW. 2007. Tumors of the urinary system. En: Withrow SJ, Vail SM (eds). Withrow and Macewen's small animal clinical oncology. $4^{\mathrm{a}}$ ed. St Louis: Elsevier. p 649-654.

6. Rossetto VJV, Brandão CVS, Ranzani JJT, Pavan PT, Mamprim MJ, Amorim RL, Donatti C. 2009. Éxerese radical de carcinoma de células transicionais de bexiga em cão: tempo de sobrevida superior a dois anos. Vet Zootecnia 16: 321-324.

7. Valsecchi JCP, Costa CMB, Costa JLO, Miyazawa MK. 2005. Cistectomia parcial no tratamento de carcinoma da bexiga em cão. Rev Cien Eletr Med Vet 2(4). [Internet]. Disponible en: http://www.revista.inf.br/veterinaria04/relatos/relato05/relato05.htm

8. Ware WW. 2006. Manifestações clínicas das doenças do trato urinário. En: Nelson RW, Couto CG (eds). Medicina interna de pequenos animais. $3^{\text {a }}$ ed. Rio de Janeiro: Elsevier. p 548-549. 